\title{
Finite Element Analysis of Synergy Effect on Concrete Beams Incorporated with Coated Reinforcement and Alternate Aggregates
}

\author{
Sakthivel Pandiaraj, Rathinasamy Velkennedy, and Soundarapandian Nagan \\ Civil Engineering Department, Thiagarajar College of Engineering, Madurai, Tamil Nadu, India \\ Correspondence should be addressed to Sakthivel Pandiaraj; kingstructure@gmail.com
}

Received 7 June 2016; Accepted 28 August 2016

Academic Editor: Hossein Moayedi

Copyright (C) 2016 Sakthivel Pandiaraj et al. This is an open access article distributed under the Creative Commons Attribution License, which permits unrestricted use, distribution, and reproduction in any medium, provided the original work is properly cited.

\begin{abstract}
The purpose of this study is to compare the ultimate load carrying capacity of conventional reinforced concrete beams with that of investigation specimen incorporated with coated reinforcement and partially with recycled aggregate and quarry dust. A novel technique of coated reinforcement delays the onset of corrosion with enhanced durability of structures. Results show that not even a film of corrosion (white rust) can be seen in the investigation specimen. There is a progressive increase in stiffness from the state of the first crack to ultimate stage and a negligible difference in ultimate load carrying capacity of the investigation specimen, when compared with the controlled specimen. Incorporation of galvanization, recycled aggregate, and quarry dust seemed to be compatible with the existing conservative concreting procedures. Experimental results are compared with the numerical solutions aided by finite element analysis (FEA by using ABAQUS).
\end{abstract}

\section{Introduction}

Reinforced concrete may be defined as a heterogeneous, strong, and durable building material; its strength and versatility is achieved by combining the best features of all the used materials, all of geological origin (composed of steel, fine, and coarse aggregates) characterized by highly nonlinear and ductile stress-strain relationship. The concrete is the second most consumed material in the world after water. It forms the basis for much of today's urban environment. 65 billion metric tons of concrete were consumed globally in 2015 , compared to 2 billion in 1950, specifically due to ruralurban migration and modernization [1]. The design of RCC structure must ensure that, under the worst loadings, the structure is safe, and during the normal working conditions the deformation of the members does not detract from the appearance, durability, or performance of the structure. Due to corrosion, RCC structure can no longer be considered to act as a linear, elastic, and homogenous material. This investigation deals with delaying the onset of corrosion by the incorporation of coated reinforcement and preserving the natural resources by the use of alternative aggregates partially, without influencing the durability of concrete structure by deploying $50 \%$ quarry dust and $50 \%$ recycled aggregate. The investigation specimens are compared with the controlled specimen, deploying black rebar with natural river sand and raw quarry rock of $20 \mathrm{~mm}$ aggregates for ultimate load carrying capacity.

FEA needs to be employed in a specific study, which depends on scale of structure, complexity of the problem, expected output, level of accuracy, and the limitations of the model. In FEA, a continuum is identified as an assemblage of finite elements with specified nodes. In precise, the analysis of structure by the finite element method is an application of the displacement/stiffness method. The finite element approach is essential, because of the large number of degrees of freedom commonly involved. A numerical simulation is one of the effective methods to analyze the load carrying capacity of concrete beams. As long as the size of the discrete elements is suitable and constitutive relation is correct, the simulation results reach the real value and satisfy the engineering requirements. Numerical simulations can overcome 
the disadvantages such as the difference between the rapid corroded components and practical engineering members, with the duration of long-term exposed natural experiments. To address this research, nonlinear finite element analysis that incorporates nonlinear material behavior as ABAQUS package is used. The ABAQUS/CAE provides a complete modeling and visualization environment for ABAQUS analysis product, with direct access to CAD models, flexibility in creating geometry, material modeling, advanced meshing, and visualization. All models are called input files. An input file has two sections, namely, model and history. The model section contains all information about the model and comes before the history section. The history section is what is done to the model. Remembering no commands for programming and automatic discretization are the advantages of ABAQUS. It is found to be an efficient methodology for handling such analysis. The proposed simulation of the material in the present study is capable of predicting the real behavior of RCC beams, in terms of load deflection, stress variation, Von Mises stress, and strain variation.

Despite the well established global research efforts, a widely accepted technique for reducing corrosion in concrete structure is coating (epoxy and hot dip galvanizing) techniques for reinforcement. Due to the inert nature and the bonding failures of epoxy, hot dip galvanizing (HDG) is considered in this research. Zinc coating protects the steel by acting as a physical barrier and cathodic protection in the event of local breakdown of the coating that exposes the bare steel. Galvanized rebars are found to be stable in the concrete without chloride contamination or carbonation [2]. Many researchers have found that the total period over which galvanization delays the onset of corrosion of reinforcing steel in concrete is of the order of 4-5 times longer than the corrosion of black steel in equivalent concrete and exposure conditions [3]. Most of the metal coats are produced by electrodeposition, but the older practice of hot dipping in which the substrate is passed through the liquefied coating metal is still important for producing zinc-coated, galvanized steel.

Galvanization provides sacrificial protection to the parent steel. In the OPC concrete, chromate treatment does not improve the corrosion resistance of the galvanized coating; instead, it retards the formation of $\mathrm{CH}_{2}$ layer which appears to be more corrosion-resistant than the chromate film itself. Therefore, galvanized rebars have to be used in the OPC concrete, in which chromate treatment is not recommended. As long as the passive state is preserved, the reinforcement does not corrode. To maintain this condition, the concrete must be sufficiently impermeable to possibly prevent the rapid transport of chemical species such as chloride, carbon dioxide, and oxygen to the reinforcement. Galvanizing produces a tough adherent alloy layer coating which enables it to be handled in much the same way as conventional black steel reinforcement [4]. The use of coated reinforcement for corrosion protection of reinforcing steel in concrete has been shown both experimentally and practically to extend the longevity of structures. An alternative method of producing a similar effect is to couple a less noble metal to the metal which needs protection. The protection is obtained at the expense of the second metal, which is a sacrificial anode and most metal coats are produced by electrodeposition. However, the older practice of hot dipping, in which the substrate is passed through the liquefied coating metal, is still important for producing zinc-coated galvanized steel [5].

In metro cities, river sand and raw mining aggregates are transported from long distance with restricted time entry. At the same time, quarry dust from mining is available at a minimum cost. Similarly, the disposal of debris from old concrete, dismantled concrete, and left over concrete and picking up the existing road surface are very hectic activities. In developed countries, recycling the concrete aggregate is very common. Usage of quarry dust and recycling of aggregates are carried out for the protection of environment and also for the conservation of natural resources. Here, safety becomes a critical issue based on the precision implied. In recent years, the wisdom of our continued huge extraction and use of aggregates from natural resources (river sand and quarrying) has been questioned worldwide.

This is mainly because of the depletion of quality primary aggregates and greater awareness of environmental protection. The use of more than $50 \%$ recycled coarse aggregates in concrete, unless carefully managed and controlled, is likely to have a negative influence on most of the concrete properties [6]. In this article, we provide an overview of the incorporation of solid waste like aggregates from dismantled concrete and residual from stone mining into useful material by recycling. If the recycling and waste management are not implemented on war footing, the landfills are not available in future due to rapid urbanization and migration. Unlike developed countries, in India, unused concrete structures, dismantled concrete, and mass concrete materials are prevalent due to transit and landfill problems, since recycling is not practiced properly.

Inert nature of coarse aggregate is an advantage for us to recycle and reuse them. The mountains become valleys by the extraction within a short period of time, leading to the deliberate destruction of valuable natural resources. In particular, if the recycling process turns to be user-friendly, then it will certainly become ecofriendly to the world. To improve the quality of recycled aggregates, water cement ratio should be altered. By using fly ash as an additional cementation material, it was found that there is no significant difference in flexural strength of conventional concrete with recycled aggregate and natural sand [7]. In this paper, saturated surface dry condition (SSD) of recycled aggregate and two-stage mixing approach (TSMA) $[8,9]$ is carried out to maintain w/c ratio, workability, and slump value. Recycling is the key component of modern waste management system and is the third component of waste hierarchy. Adhering to the principle "reduce, reuse, and recycle," it has been found that the replacement of quarry dust for fine aggregates improves the mechanical properties of concrete. When the quarry dust is used along with super plasticizers, physical and chemical properties of the quarry dust satisfy the requirements of fine aggregate [10].

Function of fine aggregate is to assist in producing workability and uniformity in concrete; it generally consists of natural sand or crushed stone with most particles passing 
through $4.75 \mathrm{~mm}$ sieve [11]. For concrete, fine aggregate fineness modulus is 2.3-3.1 [12]. River sand has been the most preferred choice for the fine aggregates component of concrete in the past, but the overuse of the material has led to some serious environmental concerns, like the depletion of conservable river sand deposits and a concomitant price increase of the material. The utilization of the quarry dust as fine aggregate in concrete is advantageous because of the benefits such as decreasing demand for the river sand and reduction of environment load and cost of concrete. Urban sprawl and emerging building construction industries are the main causes of environmental pollution leading to severe sustainable issues. Ideal percentage of the replacement of sand with the quarry dust is about $55 \%$ to $70 \%$ in the case of compressive strength [13]. Strength and corrosionresistant properties of concrete containing quarry dust as fine aggregates using inhibitor (triethanolamine at $1 \%$ to $4 \%$ by weight of cement) increased, and it offers a remarkable resistance against chemical and corrosion attack [14].

Accelerated chloride permeability tests indicate that there is no significant changes with a possible marginal improvement in sand replaced mixes. Desired results are obtained for skid and abrasion resistance with significant improvement in performance, when higher quantities of unprocessed and manufactured quarry fines were used to replace the natural sand [15]. Extraction of the river sand causes environmental degradation like removal of minerals from topsoil due to erosion and change in vegetation, leading to soil infertility problems, thereby affecting agricultural productivity. Besides, it causes changes in river courses leading to floods and alteration of river ecosystem affecting flora and fauna [16]. The specific gravity, bulk density, porosity, water absorption, silt content, impact value, and aggressive crushing value show a satisfactory performance and the compressive strength of quarry dust concrete attains the strength above $23.71 \mathrm{~N} / \mathrm{sq} \cdot \mathrm{mm}$, which makes it a suitable fine aggregate for the production of normal weight concrete [17]. Before 30 years, the river sand was available within $10 \mathrm{~km}$ of radius; now it has to be transported from a distance of $150 \mathrm{~km}$ away from workplace. In near future, river sand has to be imported like petroleum products from some other countries. Nowadays, it is rare to see river sand without silt, clay, and other impurities. Desired flexural strength is achieved at 50\% replacement of river sand with the quarry dust [18].

The quarry dust improved the strength properties of concrete which is on par with that of conventional concrete. Strength on period of 28 days of $100 \%$ replacement of sand with quarry dust is $11.8 \%$ higher than that of controlled cement mortar cube [19]. Replacement of sand by the quarry dust increases the strength of concrete with addition of inhibitor. It offers very good resistance against chemical attack and increases corrosion resistance in addition to the overall properties of concrete $[20,21]$. The quarry dust in concrete retards the workability, which can be improved by the use of admixtures, which are used to modify the properties of concrete to make them more suitable for work. Water reducing admixtures (WRA) are defined as type A in ASTM C494, used for reducing the amount of water up to $5 \%$ to $12 \%$, so as to retard the initial setting time.
Experiments are carried out as per IS 383-1970, which recommends $30-60 \%$ replacement, which improves compressive strength and workability. It is proven that the compressive, flexural strength and durability of the quarry dust concrete are nearly $10 \%$ greater than those of the conventional concrete [22]. Investigations recommend that the quarry dust can be an alternative for river sand based on workability, compressive strength, flexural strength, slump value, compaction factor, and split tensile strength [23]. It is also suggested that replacement of fine aggregate by the quarry dust up to $50 \%$ by weight has a negligible effect on the reduction of any physical and mechanical properties, while there is a saving of $56 \%$ of expenses [24]. Water absorption of quarry dust concrete is slightly higher than that of conventional concrete.

\section{Materials and Methods}

2.1. Materials. River sand with a specific gravity of 2.75 is passed through $4.75 \mathrm{~mm}$ sieve. The quarry dust, brought from mines at a cost of $10 \%$ of river sand with a specific gravity of 2.6, is filtered through $4.75 \mathrm{~mm}$ sieve (Figure 1(c)). The raw mining coarse aggregate measures about $15-20 \mathrm{~mm}$. The recycled concrete aggregate is collected from a dismantled footbridge (Figure 1(a)). Unwanted materials that adhered to the concrete are removed by hammer and jaws and then cleaned manually (Figure 1(b)). The shape of recycled aggregates is rounded and less flaky than natural aggregates, which is manually sized to $13-20 \mathrm{~mm}$. HYSD plain and galvanized-coated reinforcement of $8 \mathrm{~mm}$ for stirrups and $16 \mathrm{~mm}$ for main reinforcement are considered.

First, HYSD rebars are cleaned in caustic bath to remove organic contaminants and then pickled in dilute sulphuric acid to remove all oxidation products and then immersed in a zinc ammonium chloride solution for fluxing (Figure 2(a)). Then, galvanization (Figure 2(b)) is carried out by dipping the rebar in the molten zinc at $450^{\circ}$ (100 microns thick as per ASTM A 767M) and thickness is measured using coating thickness gauge (Figure 2(c)).

Chromating on HDG must be elucidated, and ordinary Portland cement was considered for this research with a w/c ratio of 0.45 for M20 grade concrete. Saturated surface dry (SSD) is achieved partially, since wiping needs skilled technique. Two-stage mixing approach (TSMA) is developed $[2,3]$ for improving the quality for RAC, in which it divided the mixing process into two stages, and proportionally required water is split into two parts and this water is added at different timings. TSMA aims at developing a stronger interfacial zone for the RA and hence enhancing the strength of the new interfacial transition zone (ITZ) [5]. In case of twostage mixing approach, fine aggregate and coarse aggregate are mixed initially with half of the water and then cement is added with half of the water to get the final concrete and it is necessary to maintain saturated surface dry condition of aggregate before starting the mixing operations of concrete.

2.2. Methods. Construction techniques ensure proper mixing and placing through compaction of concrete, in which they 


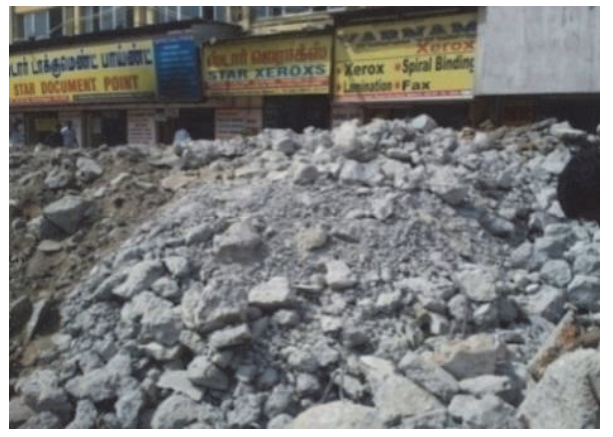

(a) Collection of aggregates from demolished footbridge

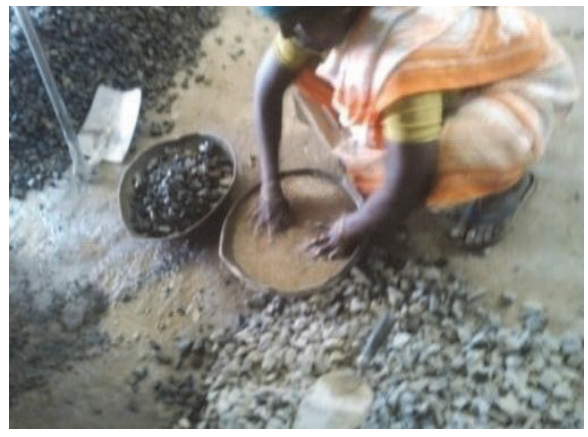

(b) Manual cleaning of aggregates

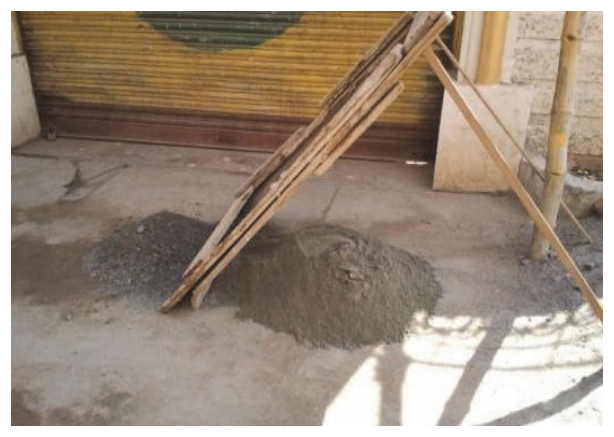

(c) Collection of quarry dust passing through $4.75 \mathrm{~mm}$ sieve

FIGURE 1: Processing stages of coarse and fine aggregates.

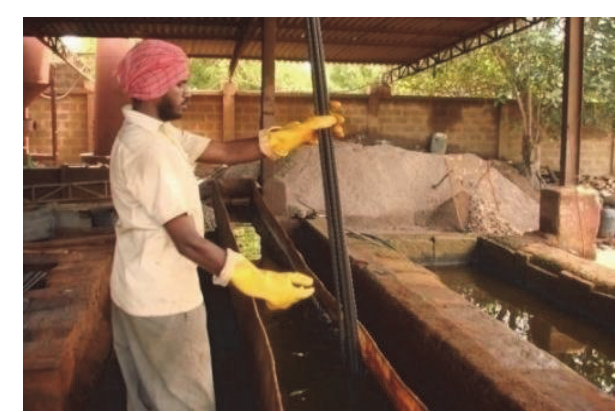

(a) HYSD rebars are cleaned in caustic fluxing

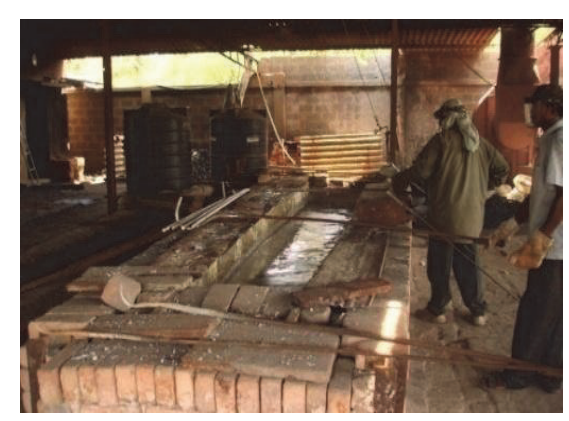

(b) Hot dipped @ $450^{\circ}$ by immersion

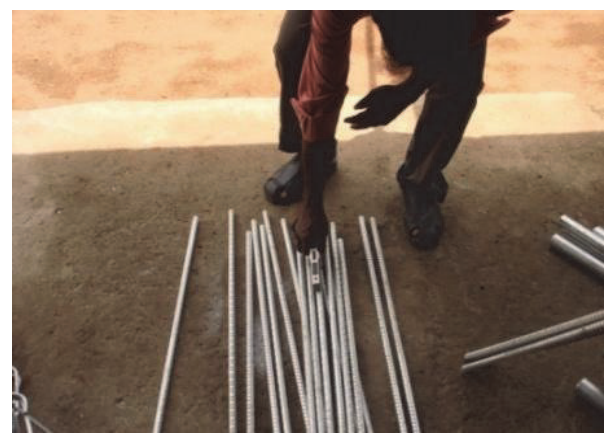

(c) Thickness is measured using gauge

FIGURE 2: Galvanizing processing stages of HYSD rebar. 
are free from defects with a minimum of joints. The quality control is an important aspect of producing durable concrete structures. Twenty-four concrete beams of size $1500 \times 230 \times$ $200 \mathrm{~mm}$ with reinforcement (Figure 3 ) are cast (12 controlled specimen and 12 investigation specimens incorporated with galvanized rebar, $50 \%$ recycled aggregate, and 50\% quarry dust) with a mix proportion (Table 3). TSMA technique (Figure 4) was implemented while mixing. After 24 hours, the controlled (SO) and investigation (RO) (Table 4) specimens are demolded and subjected to ordinary water curing for 7 days and then immersed in potable water, as shown in Figure 5. After the duration of 28 days, 3 months, 6 months, and one year, specimens are tested as per IS: 516-1964 and the test arrangements are shown in Figure 6.

Load at an initial crack for investigation specimen is less, when compared with the controlled specimen up to a period of 6 months, and gaining strength takes a lead from 6 months to one-year period. As conceptualized from the research findings from Table 7, it can be seen that investigation specimen is gaining strength after a period of six months and maintains the inflation up to one-year period. These beams resist up to a mean load of $23.03 \mathrm{t} \& 23.72 \mathrm{t}$, respectively. Ultimate load significantly rises in the investigation specimen. In the case of beam immersed in potable water in one-year period, ultimate mean load for investigation specimen (20.13t) is comparatively less, when compared with the controlled specimen $(22.33 \mathrm{t})$. Ultimate load carrying capacity is more or less identical for all the specimens with threshold sign of corrosion (red rust) seen in the controlled specimen. It is evident that no significant sign of corrosion is seen in investigation specimen, when it is immersed in potable water. Corrosion propensity, in future, can be detected by several NDT methods. There have been endless debates and research going on this. The only disadvantage in the incorporation of galvanizing is its reaction with concrete, when it becomes green; thereby, hydrogen evolution occurs and it can be reduced by chromating. Many results are obtained [2528] including compressive strength, chromating passivation, cathodic production, chloride ingress, bond stress, comparison with epoxy, ultimate bond strength, sacrificial nature, alkaline and acidic environments, deicing salts, freezing and thawing, strains and crack propagation, volume of rusts, membrane coating, and coating characteristics.

\section{Finite Element Study}

Every complete finite element analysis consists of 3 separate stages, namely, preprocessing or modeling or solver, processing of finite element analysis, and postprocessing. ABAQUS was initially designed to address the nonlinear physical behavior. As a result, the package has an extensive range of material models such as elastomeric (rubber-like) material capabilities. In this study, the modeling and simulation of the RCC beam has been executed in ABAQUS finite element analysis software (ABAQUS/CAE) in order to study its behavior under a specific loading. When developing a model for (FEA), a typical analysis process is followed. ABAQUS/CAE is capable of preprocessing, postprocessing, and monitoring the processing stage of the solver. However, the first stage can also be performed by other compatible CAD software or even a text editor. Parameters are defined initially to perform the analysis. In this article material properties are defined and mesh is also generated. Boundary conditions for the model are defined and finally the model is submitted to the solver and the kind of analysis is defined. It is imperative that the FEA be recognized as simulation, not as reality. Moreover, the obtained output results from the FEA are only approximations; namely, there is a difference between the finite element solution and the exact solution. The generated models were validated against all respective experimental results.

Reinforcement Model. Elastoplastic bilinear model is used for the steel used in main reinforcement and stirrups (Figure 7). Bilinear stress-strain behavior is given as input to the model. Two-noded beam element (B31-beam, 3-dimensional, and first-order interpolation) of linear geometric order is used to model the reinforcement and stirrups.

3.1. Elements. The ABAQUS element library provides a complete geometric modeling capability. For this reason, any combination of elements can be used to design the model. All elements use numerical integration to allow complete generality in material behavior. Element properties can be defined as general section behaviors or each cross section of the element can be integrated numerically, so that nonlinear response can be tracked accurately when needed and element configuration is shown in Table 5.

3.2. Damage Model for Concrete. ABAQUS software provides the capability of simulating the damage using either of the three crack models for concrete: concrete model, brittle crack concrete model, and concrete damaged plasticity (CDP). CDP model is selected in this study, since this technique has the potential to represent complete inelastic behavior of concrete both in tension and in compression including damage characteristics. Moreover, only CDP model can be used both in ABAQUS/STANDARD and in ABAQUS/EXPLICIT and thus transfer of results between the two is enabled. CDP model assumes that the two main failure mechanisms in concrete are the tensile cracking and the compressive crushing. The CDP model is a modification of the Drucker-Prager strength hypothesis. This was later modified by Lubliner, Lee, and Fenvas as shown in Figure 8.

According to the modifications, the failure surface in the deviatoric cross section need not to be a circle and it is governed by the parameter $K_{c}$. Physically, the parameter $K_{c}$ is interpreted as a ratio of the distances between the hydrostatic axis and, respectively, the compression meridian and the tension meridian in the deviatoric cross section. The ratio is always higher than 0.5 and when it assumes the value of 1 the deviatoric cross section of the failure surface becomes a circle. The CDP model recommends assuming $K_{c}=2 / 3$. The parameter eccentricity can be calculated as a ratio of tensile strength to compressive strength. The CDP model recommends using $e=0.1$. When $e=0$, the surface in the meridional 


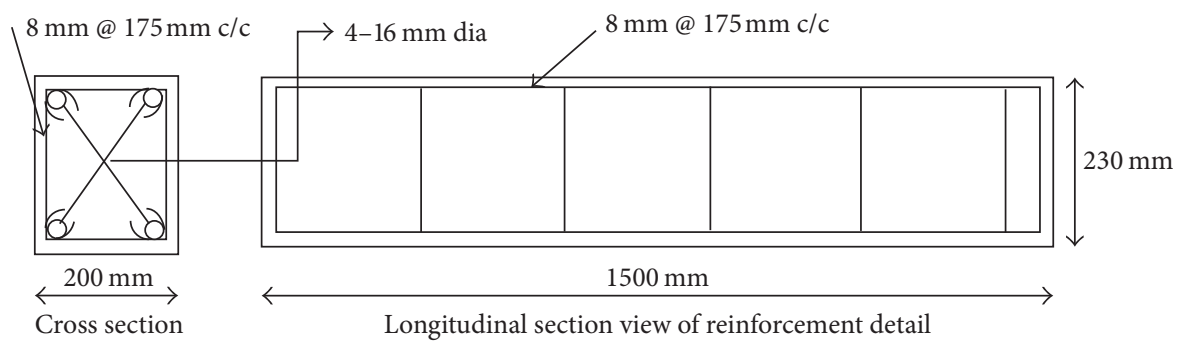

FIgURE 3: Typical reinforcement details for the beams.
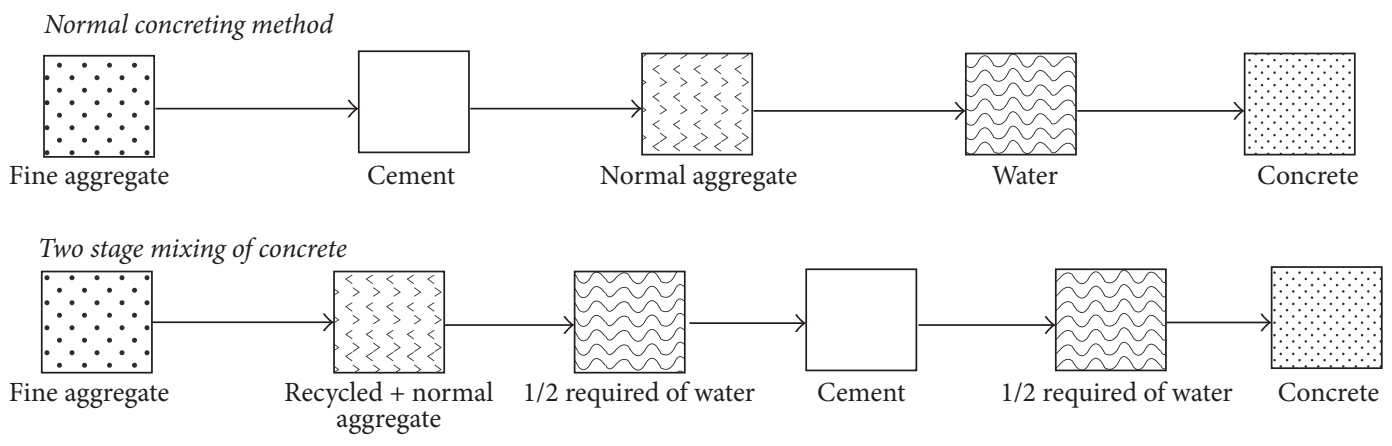

FIGURE 4: Comparison of normal mixing and two-stage mixing approach of concrete.
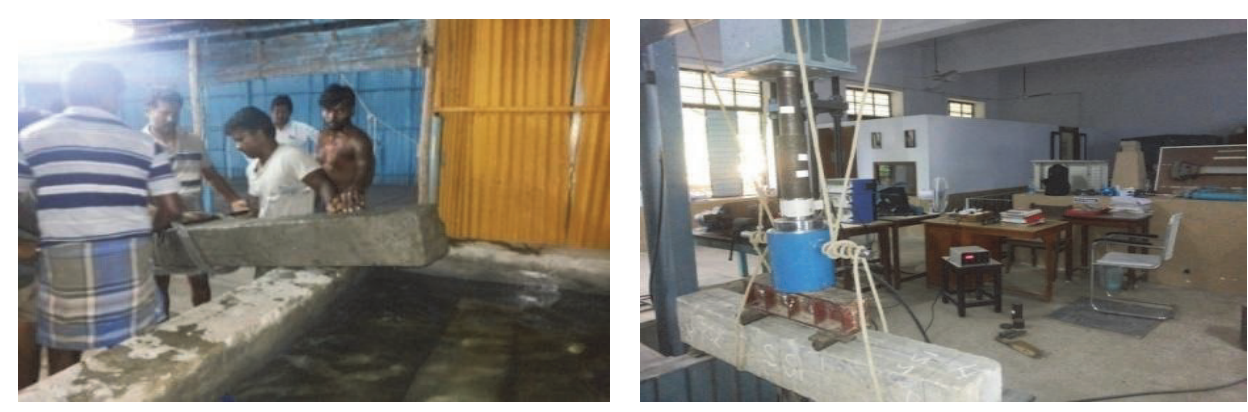

FIgURE 5: Removal of beams from potable water and experimental setup of beam.

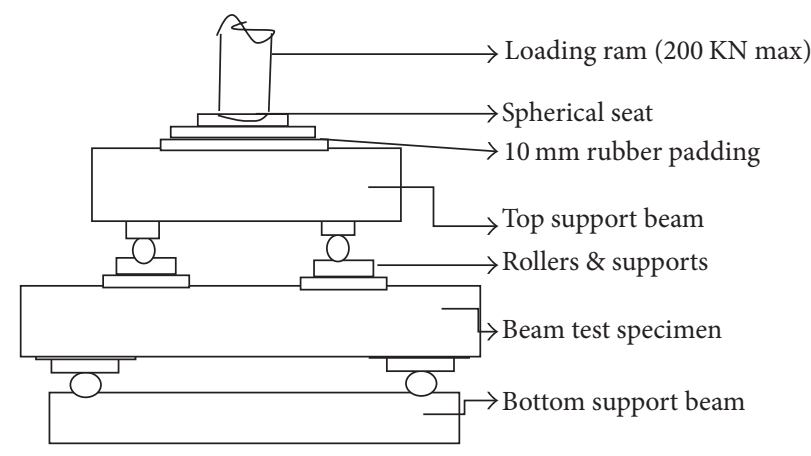

FIGURE 6: Test arrangements for beam. 


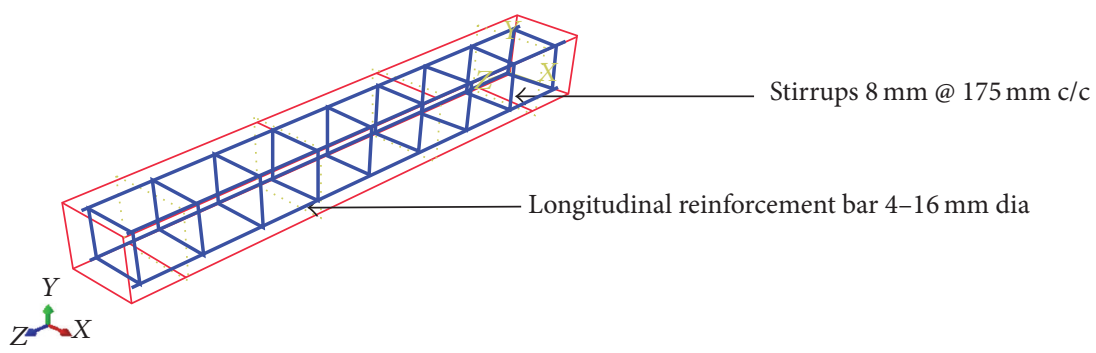

FIgURE 7: Typical reinforcement details of the FE Model beam.

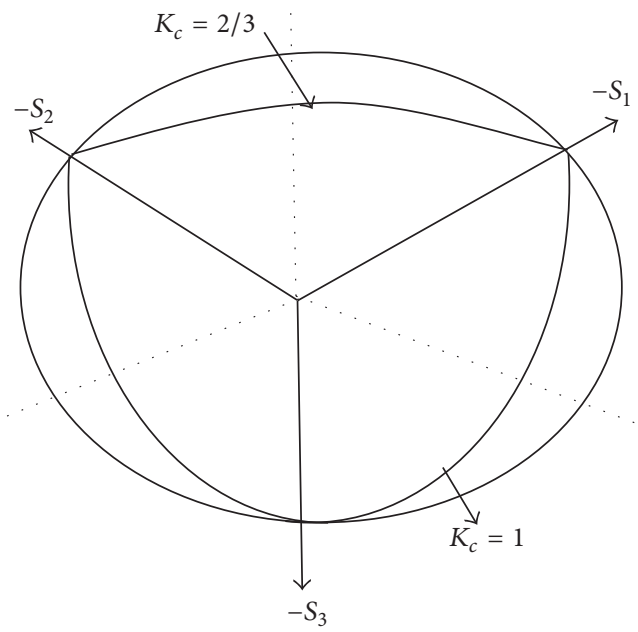

FIGURE 8: Deviatoric cross section of failure surface in CDP model.

plane becomes a straight line. Another parameter describing the state of material is the point in which the concrete undergoes failure under biaxial compression (Figure 10). The last parameter characterizing the performance of concrete under compound stress is dilation angle, that is, the angle of inclination of the failure surface towards the hydrostatic axis, measured in the meridional plane. Hyperbolic surface of plastic potential in meridional plane is shown in Figure 9.

Physically, dilation angle, $\Psi$, is interpreted as a concrete internal friction angle, as represented in Figure 10. Usually, it is assumed that $\Psi=36^{\circ}, 0$ or $\Psi=45^{\circ}, 0$. The unquestionable advantage of the CDP model is the fact that it is based on the parameters having an explicit physical interpretation. The strength of concrete under biaxial is shown in Figure 10. The CDP model's parameters characterizing its performance under compound stress are given in Table 6.

3.3. Drucker-Prager Model. Besides reviewing the yield surface in principal stress space, as shown earlier, one can also look at the yield surface along the plane defined by the effective stress (SEQV or $q$ or seqv) and hydrostatic pressure (HPRES or sm). The linear Drucker-Prager yield surface would look as illustrated in Figure 11.

The two main items that are required for the linear Drucker-Prager case are the slope ("angle of internal friction") and the value at which it intersects the $y$-axis

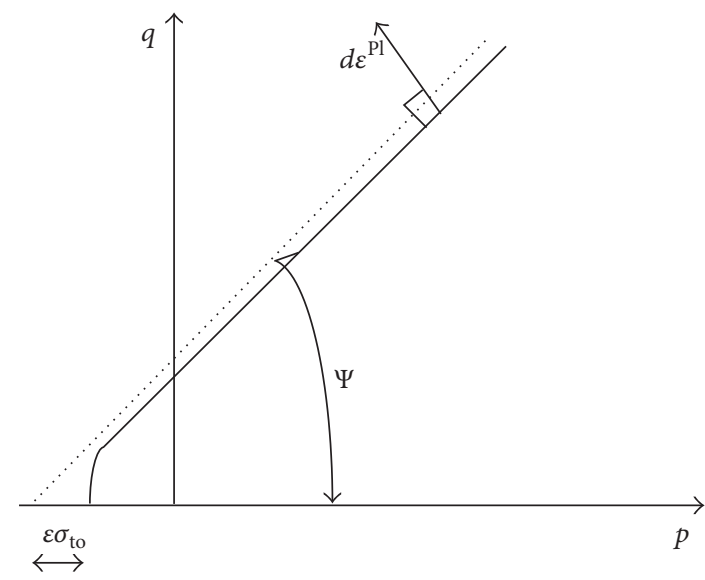

FIGURE 9: Hyperbolic surface of plastic potential in meridional plane.

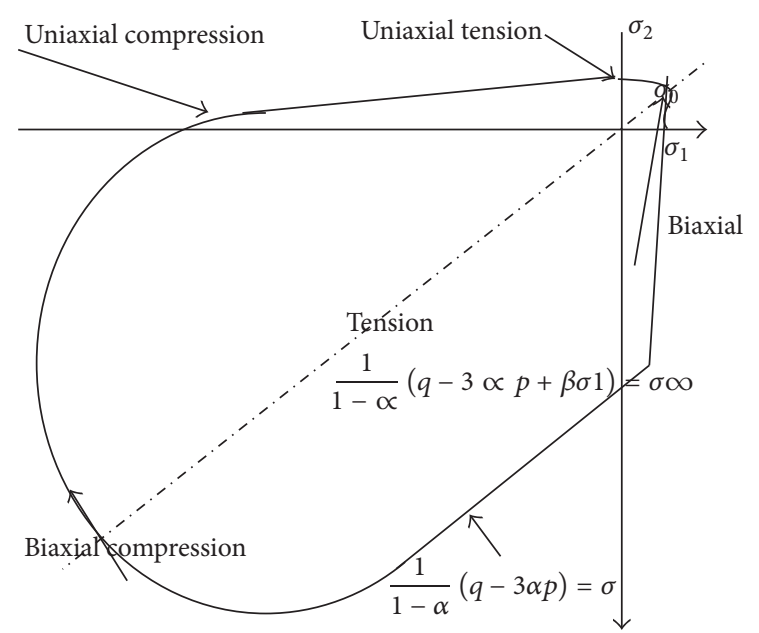

FIGURE 10: Strength of concrete under biaxial stress in CDP model.

(i.e., the yield strength at zero hydrostatic pressure, related to the "cohesion value").

(a) The cohesion value $c$ is related to the yield strength $\sigma_{y}$ via the relationship $c=(\sqrt{3(3-\sin \theta)} / 6 \cos \theta) \sigma_{y}$. Note that the intersection occurs at $\sigma_{y} / \sqrt{3}$ (the TB, DP yield function is defined with $q / \sqrt{3})$ and so sometimes this is rewritten as $c=((3-\sin \theta) /$ $6 \cos \theta) \sigma_{y}$. 


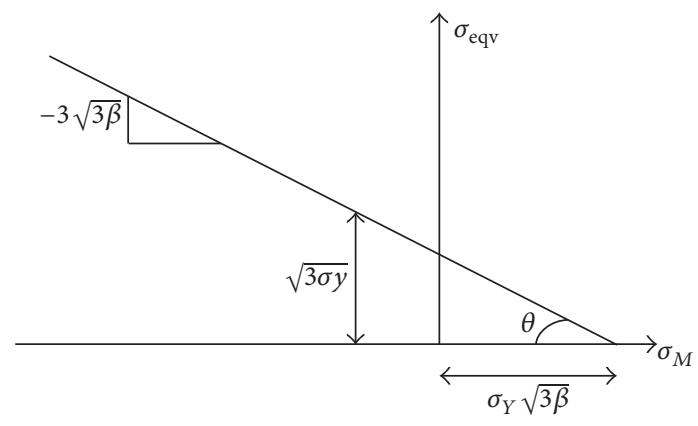

FIGURE 11: Linear Drucker-Prager yield surface.

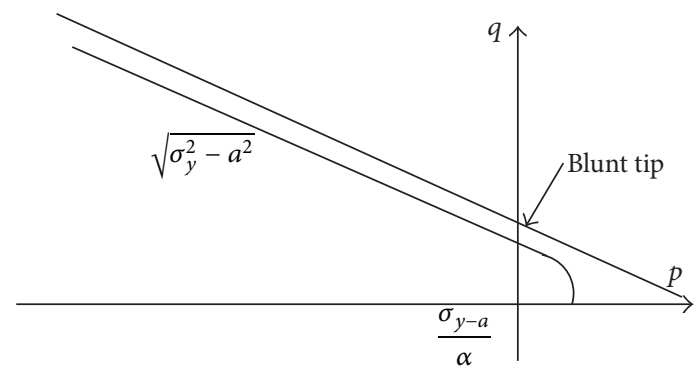

FIGURE 12: Hyperbolic yield surfaces on the right also create a blunt tip.

(b) The angle of internal friction " $q$ " describes the slope of the yield surface. One can imagine that if the angle is zero, this will imply no dependence on hydrostatic pressure; effectively, this would change the behavior to the Von Mises yield surface.

(c) There is actually a third parameter for the DruckerPrager material model: the dilatancy angle " $\theta$ " that describes the flow potential. If $\theta=\theta f$, the flow is associative. If $\theta f=0$, no inelastic volumetric strains will be produced.

3.3.1. Extended Drucker-Prager Model. The extended Drucker-Prager (TB, EDP) is meant to address some shortcomings of the basic Drucker-Prager model, namely, the use of perfectly plastic behavior and the requirement of a linear yield surface. The extended Drucker-Prager model was introduced at ANSYS 10.0 for the use with PLANE182/183 (except for plane stress) and SOLID185/186/187.

(a) A linear, power law or hyperbolic yield surface can be specified with the TBOPT argument of the TB, EDP command. This affects the shape of the shear envelope (yield surface); note how the power law and hyperbolic yield surfaces on the right also create a 'blunt' tip of the cone (Figure 12), which is helpful in preventing numerical difficulties in tension.

(b) Strain-hardening behavior is specified by adding an isotropic hardening plasticity model to the same material ID. Although yield strength is the input in $\mathrm{TB}, \mathrm{EDP}$, if anisotropic hardening law is associated

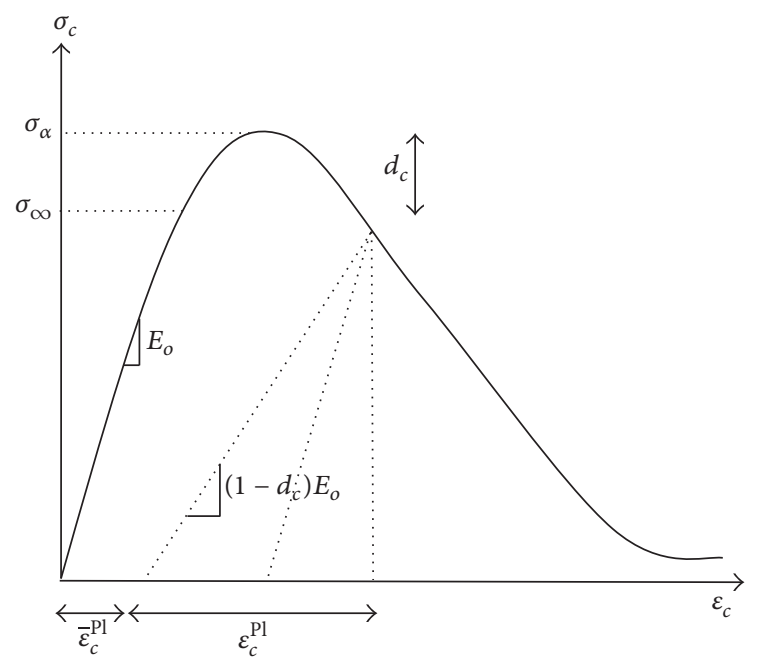

FIGURE 13: Stress-strain curve for uniaxial compression.

with the same material, the yield strength and subsequent strain-hardening behavior will be controlled by the isotropic hardening input.

(c) A flow potential also needs to be specified, although the user can select a different flow potential.

3.4. Load Deflection Curve. Deflection was measured at midspan at the centre of the bottom face of the beam. The load deflection curve for the beam from the numerical results has positive agreement with experimental data.

3.5. Stress-Strain Curve. In stress-strain curve for uniaxial compression, inelastic strains are used in the CDP model. In order to determine them, the elastic part (corresponding to the undamaged model) should be reduced from the total strains, as shown in Figure 13. Stress-strain curve for uniaxial tension cracking strain is used in CDP model. The main aim is to take into account the phenomenon called tension stiffening. Concrete under tension is not regarded as a brittle elastic material and such phenomena as aggregate interlocking in a crack and concrete to steel adhesion between cracks are taken into account. This assumption is valid when the pattern of cracks is fuzzy. Then the stress in the tension zone decreases gradually. The strain after cracking is defined as the difference between the total strain and the elastic strain for the undamaged material as shown in Figure 14.

\subsection{Constitutive Model}

Concrete Model and Loading Profile. Eight-noded, hexahedral brick element of linear geometric order with reduced or one-point integration (C3D8R-continuum, 3-dimensional, 8 nodes, and reduced integration) is used for concrete model (Figure 15). Behavior of concrete in compression including strain softening has been modeled according to Attard and Setunge [29], which has been shown to be applicable to a broad range of in situ concrete strength from $20 \mathrm{MPa}$ to 


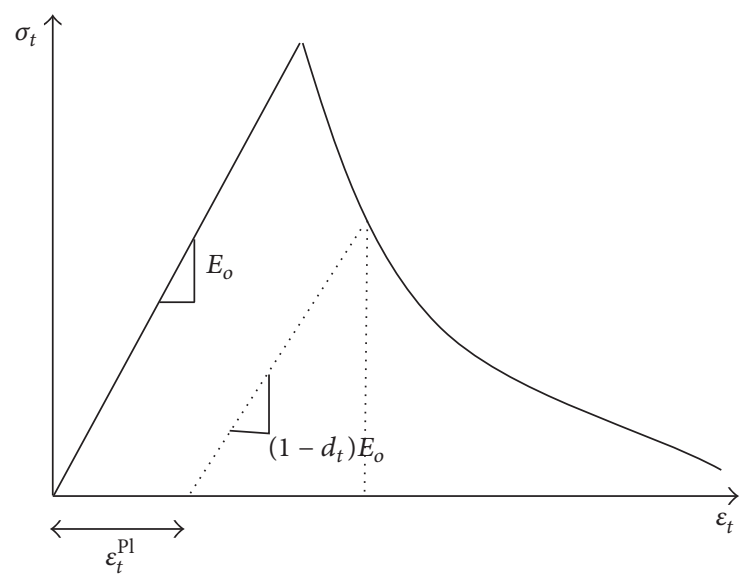

FIGURE 14: Stress-strain curve for uniaxial tension.

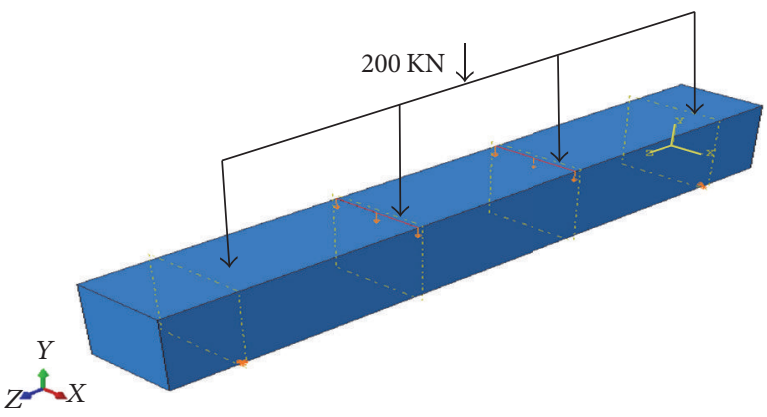

FIgURE 15: FE model of beam specimen.

$130 \mathrm{MPa}$. Postpeak stress-strain behavior is defined using tension stiffening option. To consider the postcracking resistance in tension, the model proposed in [30] is adopted. Loading is given at one-third effective span. Simply supported boundary conditions are provided at $125 \mathrm{~mm}$ from each end of the beam.

3.7. Meshing. All the elements in the model are provided with uniform and fine mesh size in order to obtain the accuracy of FE results. The mesh element used for modeling of concrete and steel are 8-noded solid brick element (C3D8R) and 3D beam element (B31), respectively. Full bond is considered between reinforcement and surrounding concrete in the FE model. Figure 16 shows the typical mesh of FE model of beam specimens. Modeling and mesh generation are developed using the same techniques for all specimens.

3.8. Maximum Principal Stress. The failure of a material will occur when the maximum principal tensile stress $\left(\sigma_{1}\right)$ in the complex system reaches the value of the maximum stress at the elastic limit in simple tension or the minimum principal stress reaches the value of the maximum stress at the elastic limit in simple compression.

Let, in a complex three-dimensional stress system, $\sigma_{1}, \sigma_{2}$, and $\sigma_{3}$ be principal stresses at a point in three perpendicular

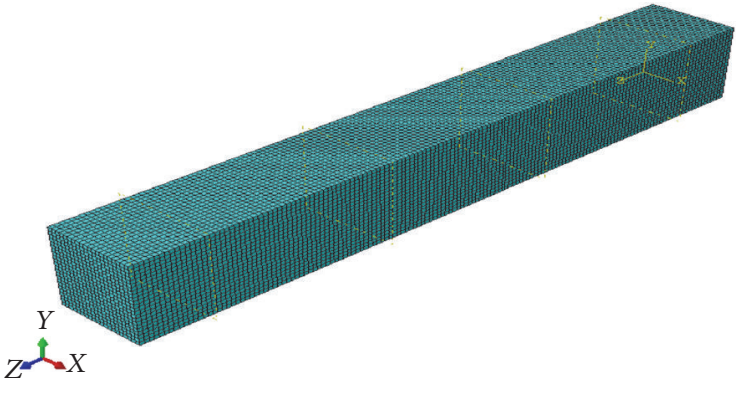

FIGURE 16: Modeling and mesh of beam specimen.

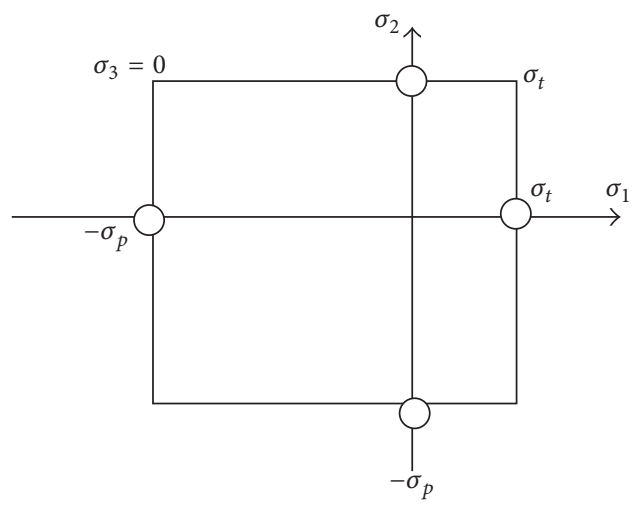

FIGURE 17: Principal stress hypothesis.

directions. The stresses $\sigma_{1}$ and $\sigma_{2}$ are tensile and $\sigma_{3}$ is compressive. Also $\sigma_{1}$ is more than $\sigma_{2} . \sigma_{t}$ is tensile stress at elastic limit in simple tension and $\sigma_{c}$ is compressive stress at elastic limit in simple compression.

Then, according to this theory, the failure will take place if $\sigma_{1} \geq \sigma_{t}{ }^{*}$ in simple tension and $\left|\sigma_{3}\right| \geq \sigma_{c}$ in simple compression, where $\left|\sigma_{3}\right|$ represents the absolute value of $\sigma_{3}$. This is the simplest and oldest theory of failure and is known as Rankine's theory. If the maximum principal stress $\left(\sigma_{1}\right)$ is the design criterion, then maximum principal stress will not exceed the permissible stress $\left(\sigma_{t}\right) \sigma_{1}=\sigma_{t}$, where, $\sigma_{t}$ is the permissible stress and is given by $\sigma_{t}=\sigma_{t}{ }^{*} /$ safety factor (Figure 18).

3.8.1. Principal Stress Hypothesis. A principal plane is any plane, in which the shear stresses are zero. The normal stresses that are acting on this plane are therefore the principal stresses. Yielding occurs when the state of stress is at the boundary of the rectangle. The associated failure surface in principal stress space is represented by a cube (Figure 17).

The principal hypothesis predominantly serves to describe brittle failure of materials. For tensile loading, we generally associate with it the process of decohesion along cross sections perpendicular to the largest principal stress. The hypothesis neglects the influence of the two other principal stresses onto failure; its applicability hence is quite limited.

3.9. Maximum Principal Strain. Yield occurs when the maximum principal strain reaches the strain corresponding to 

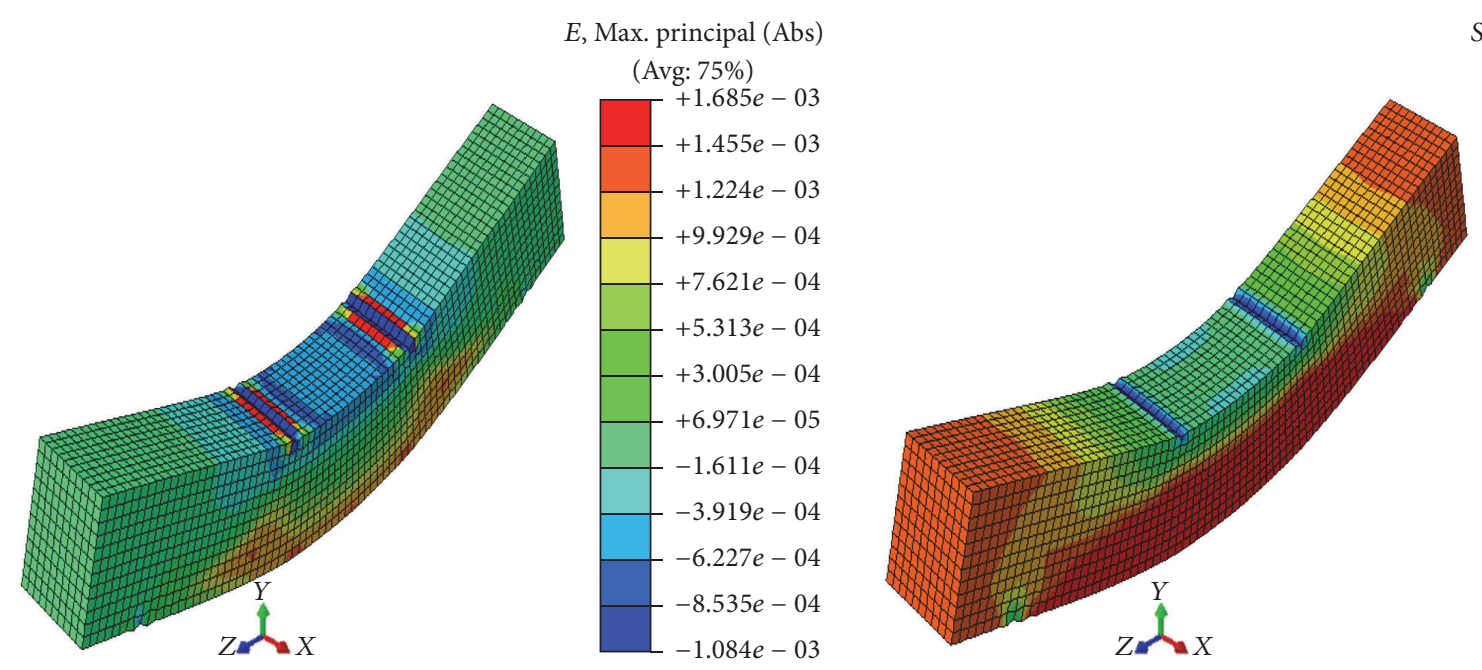

S, Max. principal (Abs)

FIGURE 18: Maximum principal stress for controlled and investigation specimen.
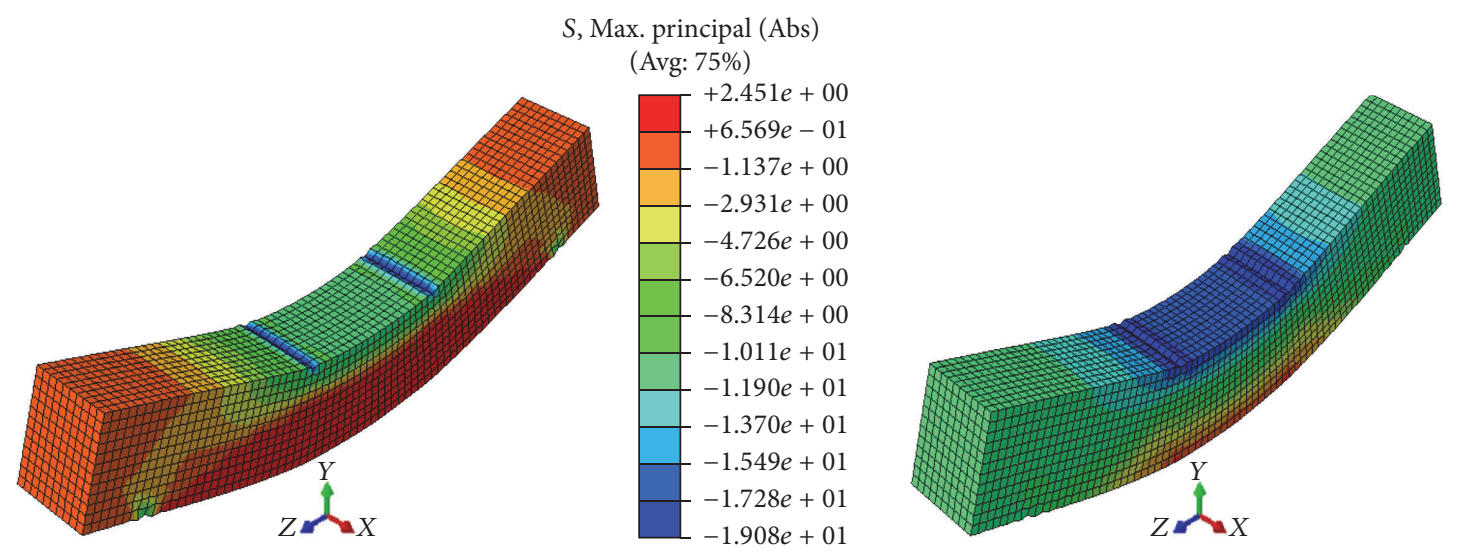

E, $E 33$

(Avg: $75 \%)$

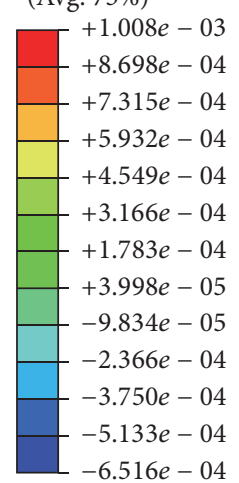

FIGURE 19: Maximum principal strain for controlled and investigation specimen.

the yield point during a simple tensile test. In terms of the principal stresses this is determined by the following (Figure 19):

$$
\sigma_{1}-V\left(\sigma_{2}+\sigma_{3}\right) \leq \sigma_{y}
$$

3.9.1. Principal Strain Hypothesis. Failure occurs when the maximum principle strain reaches the critical value $\varepsilon t$. If linear elastic behavior is assumed until failure and the critical tensile stress is introduced, the failure surface will be represented by a pyramid with three planes centered on the hydrostatic axis with its apex as follows (Figure 20):

$$
\sigma_{1}=\sigma_{2}=\sigma_{3}=\frac{\sigma_{t}}{(1-2 v)}
$$

3.10. Von Mises Stress. It suggests that the yielding of materials begins, when the second deviatoric stress invariant $J_{2}$ reaches a critical value. Prior to yield, material response is assumed to be elastic (Figure 21). Von Mises stress or equivalent tensile stress is $\left(\sigma_{v}\right)$ a scalar stress value that can be computed from the Cauchy stress tensor. In this case, a material is said to start yielding when its Von Mises stress reaches a critical value, known as the yield strength $\sigma_{y}$. The Von Mises stress is used to predict the yielding of materials under any loading condition from the results of simple uniaxial tensile tests (Figure 22). Because the Von Mises yield criterion is independent of the first stress invariant, it is applicable for the analysis of plastic deformation for ductile material such as metals, as the onset of yield for these materials does not depend on the hydrostatic component of the stress tensor. $k=\sigma_{y} / \sqrt{3}$. The total shear strain energy due to principal stresses $\sigma_{1}, \sigma_{2}$, and $\sigma_{3}$ in a stressed material is given as follows:

$$
\frac{1}{12 C}\left[\left(\sigma_{1}-\sigma_{2}\right)^{2}+\left(\sigma_{2}-\sigma_{3}\right)^{2}+\left(\sigma_{3}-\sigma_{1}\right)^{2}\right]
$$

The simple tension test is a uniaxial stress system, which means the principal stresses are $\sigma_{1}, 0$, and 0 . At the elastic limit, the tensile stress in simple test is $\sigma_{t}{ }^{*}$. Hence, at the elastic limit in simple tension test, the principal stresses are 


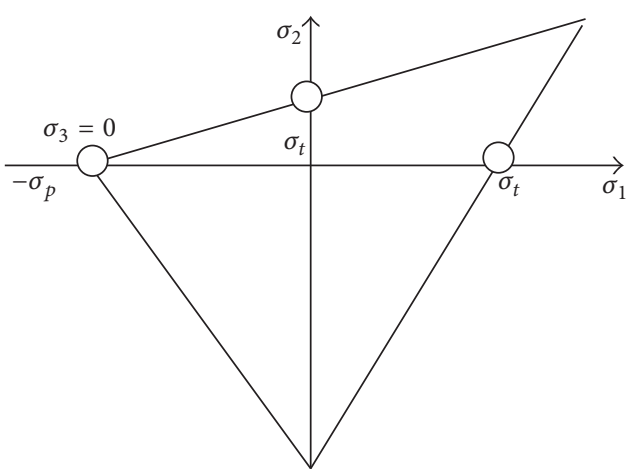

FIGURE 20: Principal strain hypothesis.

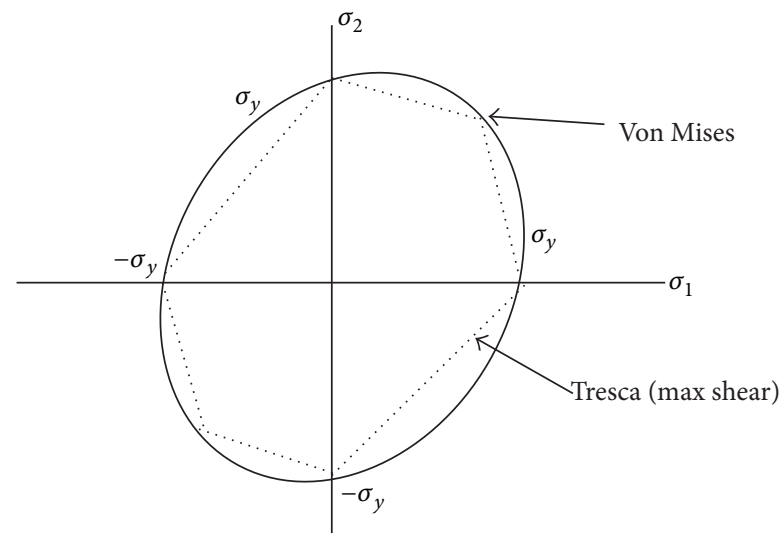

FIgUre 21: Von Mises yield curve.

$\sigma_{t}{ }^{*}, 0$, and 0 . The shear strain energy per unit volume at the elastic limit in simple tension will be as follows:

$$
\begin{aligned}
& =\frac{1}{12 C}\left[\left(\sigma_{1}-0\right)^{2}+(0-0)^{2}+\left(0-\sigma_{t}^{*}\right)^{2}\right] \\
& =\frac{1}{12 C}\left[2 \times\left(\sigma_{t}^{*}\right)^{2}\right]
\end{aligned}
$$

$\left[\right.$ Here, $\left.\sigma_{1}=\sigma_{t}^{*}, \sigma_{2}=0, \sigma_{3}=0\right]$.

For the failure of the material,

$$
\begin{aligned}
& \frac{1}{12 C}\left[\left(\sigma_{1}-\sigma_{2}\right)^{2}+\left(\sigma_{2}-\sigma_{3}\right)^{2}+\left(\sigma_{3}-\sigma_{1}\right)^{2}\right] \\
& \quad \geq \frac{1}{12 C}\left[2 \times\left(\sigma_{t}^{*}\right)^{2}\right] \\
& {\left[\left(\sigma_{1}-\sigma_{2}\right)^{2}+\left(\sigma_{2}-\sigma_{3}\right)^{2}+\left(\sigma_{3}-\sigma_{1}\right)^{2}\right] \geq 2 \times\left(\sigma_{t}{ }^{*}\right)^{2} .}
\end{aligned}
$$

For actual design instead of $\sigma_{t}{ }^{*}$, the allowable stress $\left(\sigma_{t}\right)$ in simple tension should be used where $\sigma_{t}=\sigma_{t}{ }^{*} /$ Safety factor.

Here for the design purpose, the following equation should be used:

$$
\left[\left(\sigma_{1}-\sigma_{2}\right)^{2}+\left(\sigma_{2}-\sigma_{3}\right)^{2}+\left(\sigma_{3}-\sigma_{1}\right)^{2}\right] \geq 2 \times\left(\sigma_{t}\right)^{2} .
$$

TABLE 1: Properties of ingredients used in concrete.

Specific gravity of cement $\quad 3.15$

Specific gravity of fine aggregate $\quad 2.5$

Specific gravity of coarse aggregate $\quad 3.00$

Specific gravity of fine aggregate (quarry 2.65

dust)

Specific gravity of coarse aggregate

(recycled coarse aggregate)

2.6

Maximum size of coarse aggregate

$20 \mathrm{~mm}$

Maximum w/c ratio

0.45

Workability

$100 \mathrm{~mm}$

Exposure condition

Mild

Type of coarse aggregate

Crushed angular

For a two-dimensional stress system, $\sigma_{3}=0$; hence, the equation becomes as follows:

$$
\begin{aligned}
{\left[\left(\sigma_{1}-\sigma_{2}\right)^{2}+\left(\sigma_{2}\right)^{2}+\left(-\sigma_{1}\right)^{2}\right] } & \geq 2 \times\left(\sigma_{t}\right)^{2} \\
\sigma_{1}^{2}+\sigma_{2}^{2}-2 \sigma_{1} \sigma_{2}+\sigma_{2}^{2}+\sigma_{1}^{2} & =2 \times \sigma_{t}^{2} \\
2\left(\sigma_{1}^{2}+\sigma_{2}^{2}-\sigma_{1} \sigma_{2}\right) & =2 \times \sigma_{t}^{2} \\
\sigma_{1}^{2}+\sigma_{2}^{2}-\sigma_{1} \sigma_{2} & =\sigma_{t}^{2}
\end{aligned}
$$

\section{Test Results and Discussions}

It is observed in most of the models that the beams yield at the flanges and collapse at the midspan. Failure at the midspan is more critical than at the support. Buckling, localized failure, and concentrated stresses also occur at the bottom flanges at the support due to boundary condition details. It is inferred from Table 1 that the specific gravity of quarry dust is negligibly less, when compared with river sand. Zero absorption is observed in river sand, when compared with the quarry dust (1.32\%). Moisture content is significantly more in river sand, when compared with the quarry dust. It is learnt that there is a progressive increase in the stiffness of the investigation specimen from the stage of initial crack till the ultimate stage in all periods. Stress, strain, Young's Modulus, and load at elasticity limit for coated and uncoated reinforcement are same, when tensile test is carried out for reinforcement (Table 2).

The use of FEA model is much faster and extremely costeffective. This helps in refining the analytical tools, so that even without experimental proof or check the complex nonlinear behavior can be predicted. ABAQUS can monitor and capture the shape and propagation of cracks during loading till failure. The agreement between the numerical simulations and experimental findings demonstrates the overall accuracy and reliability of the analytical models in predicting the response of this new type of structural elements. Based on the results of the numerical simulations and comparisons with experimental data, the following conclusions are reached. Numerical simulations with parametric FEA models use 

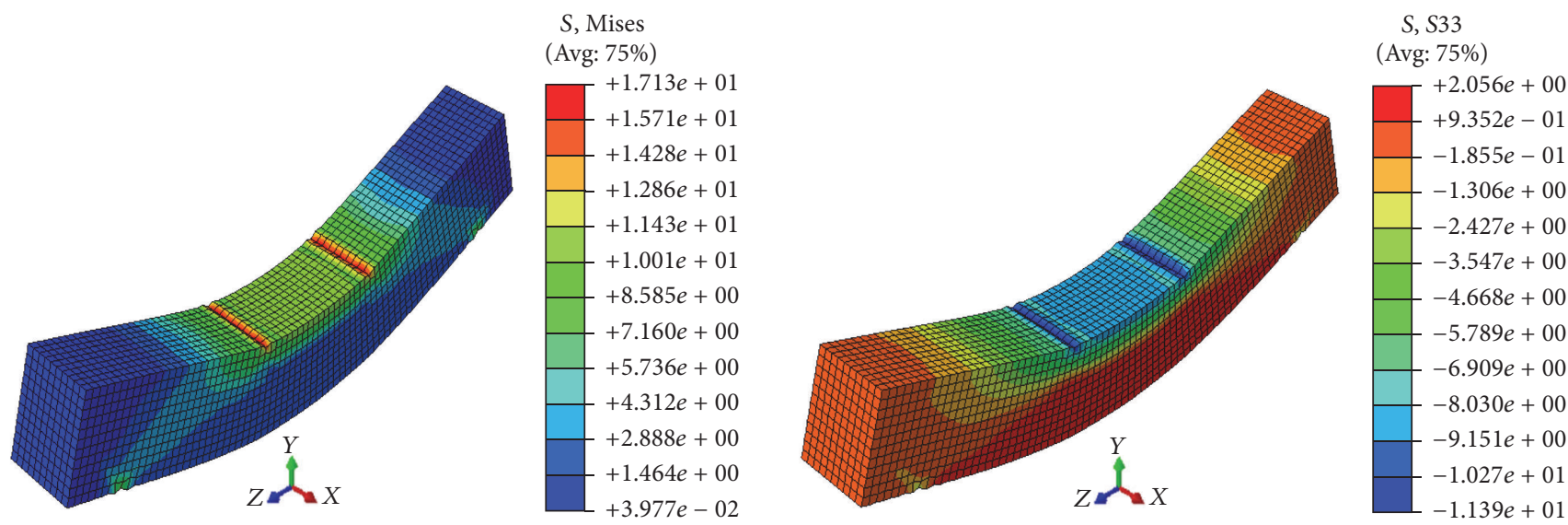

FIGURE 22: Von Mises stress for controlled and investigation specimen.

TABLE 2: Tensile test for reinforcement (galvanized and plain rebar).

\begin{tabular}{lcccccc}
\hline Material & $\begin{array}{c}\text { Original length } \\
(\mathrm{mm})\end{array}$ & $\begin{array}{c}\text { Change in } \\
\text { length }(\mathrm{mm})\end{array}$ & $\begin{array}{c}\text { Extension } \\
(\mathrm{mm})\end{array}$ & Strain & $\begin{array}{c}\text { Load at elasticity } \\
\text { limit }(\mathrm{KN})\end{array}$ & $\begin{array}{c}\text { Stress } \\
\mathrm{KN} / \mathrm{mm}^{2}\end{array}$ \\
\hline Reinforcement & 1000 & 1028 & 28 & 0.028 & 118 & $\begin{array}{c}\text { Young's } \\
\text { modulus }(E) \\
\mathrm{KN} / \mathrm{mm}^{2}\end{array}$ \\
\hline
\end{tabular}

TABLE 3: Mix proportion.

\begin{tabular}{lccc}
\hline Cement & FA & CA & Water \\
\hline $360 \mathrm{~kg} / \mathrm{m}^{3}$ & $590 \mathrm{~kg} / \mathrm{m}^{3}$ & $1230 \mathrm{~kg} / \mathrm{m}^{3}$ & $163 \mathrm{lit} / \mathrm{m}^{3}$ \\
1 & 1.63 & 3.42 & 0.45 \\
\hline
\end{tabular}

TABLE 4: Specimen identification.

\begin{tabular}{ll}
\hline $\begin{array}{l}\text { Identification of } \\
\text { specimen }\end{array}$ & Beam description \\
\hline $\begin{array}{l}\text { Controlled specimen } \\
\text { SO }\end{array}$ & $\begin{array}{l}\text { Incorporated with HYSD black rebar, } \\
\text { river sand, and raw rock 20 mm aggregate } \\
\text { are exposed to potable water }\end{array}$ \\
$\begin{array}{l}\text { Investigation } \\
\text { specimen RO }\end{array}$ & $\begin{array}{l}\text { 50\% recycled coarse aggregate are } \\
\text { exposed to potable water }\end{array}$ \\
\hline
\end{tabular}

powerful and robust tools for comprehensive investigations of bearing capacities and failure mechanisms of RC structures. They reliably evaluate global parameters like load deflection curve and deflected shape in Figures 23, 24, and 26 which is close to experimental values. Simulations open the view to the inside of structures, stresses, and strains and overall spatial distributions and developments over loading histories to properly understand inner bearings and redistribution mechanisms. Experiments and numerical investigations have to go simultaneously, since experimental verifications of basic numerical data are still indispensable to ensure reliable numerical results.

\section{Conclusions}

All our experiments are quite effective and have yielded positive results. Judicious use of galvanized rebar, recycled aggregates, and the quarry dust is unavoidable in near future. Investment for galvanization can be equalized by partial replacement of aggregates with inflated durability and serviceability of the structure by delaying the onset of corrosion. Nevertheless, statistical analysis of these results at the $95 \%$ confidence level confirms that there is no significant difference in the flexural capacity of beams. There is generally little or no evidence of red rust corrosion or negligible film of corrosion seen even after one year in the coated reinforcement but only the superficial corrosion of the zinc coating is identified, perhaps $0.005 \%$ loss of coating thickness at the end of one-year period.

(1) From the experimental study, it can be concluded that partial incorporation of the quarry dust and recycled aggregate is well appropriate for medium graded concrete for better performance in terms of strength and economy over controlled specimen. Incorporation of TSMA, saturated surface dry condition of recycled aggregates, and adding admixtures will improve the workability and ensure the desired strength. The scope for further work is related to the finding of userfriendly mechanism to recycle the aggregates in massive quantity. Easily available admixture should be found to maintain the w/c ratio; thereby workability problem can be solved. If the galvanization is carried out for huge quantity, then the investment will be less. If all these advantageous techniques are practiced, then user-friendliness turns to be ecofriendliness. A small amount of premium costs may be acceptable, since incorporation of galvanization, recycling, and the use of quarry dust will certainly emerge as very useful and relevant concepts in future. 
TABLE 5: Element configuration.

\begin{tabular}{lcccc}
\hline Element type & Elements & Nodes & Geometric order & Degrees of Freedom \\
\hline $\begin{array}{l}\text { 8-noded solid brick element for concrete } \\
\text { (C3D8R) }\end{array}$ & 9120 & 11011 & Linear & $33033(3$ translation) \\
3D beam element for reinforcement (B31) & 598 & 602 & Linear & $3612(3$ translation + 3 rotation) \\
\hline
\end{tabular}
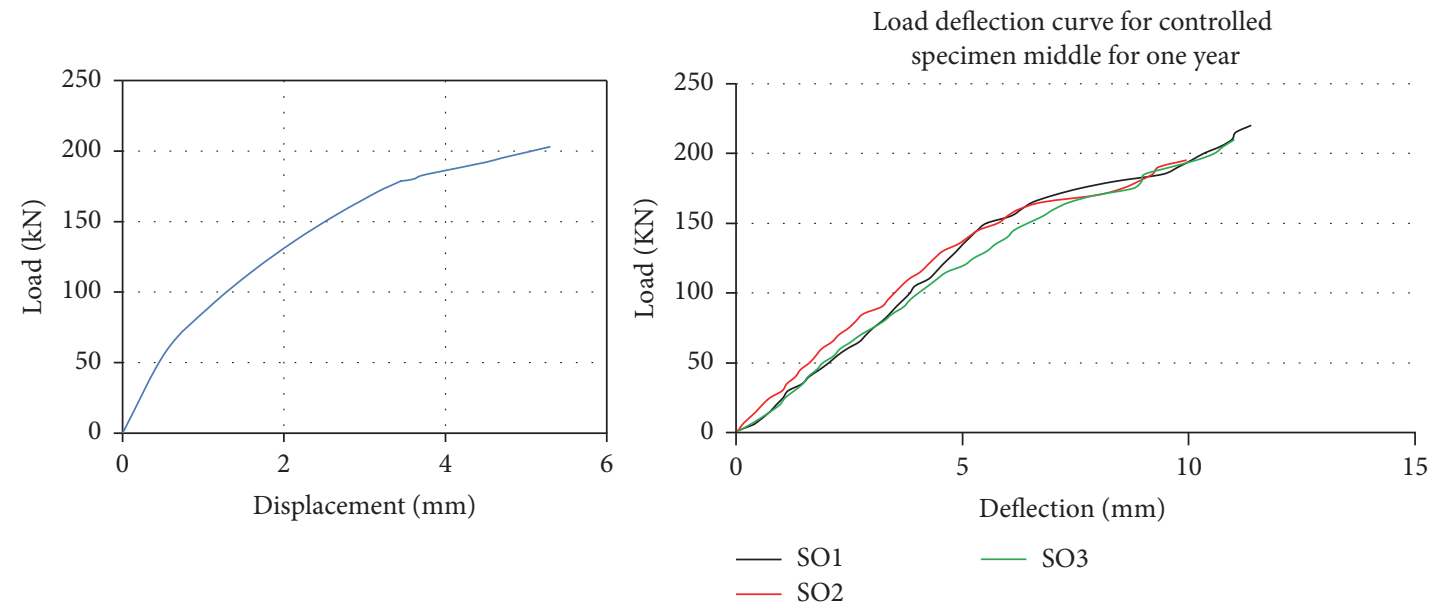

Figure 23: FEA and experimental load displacement curve for controlled specimen.
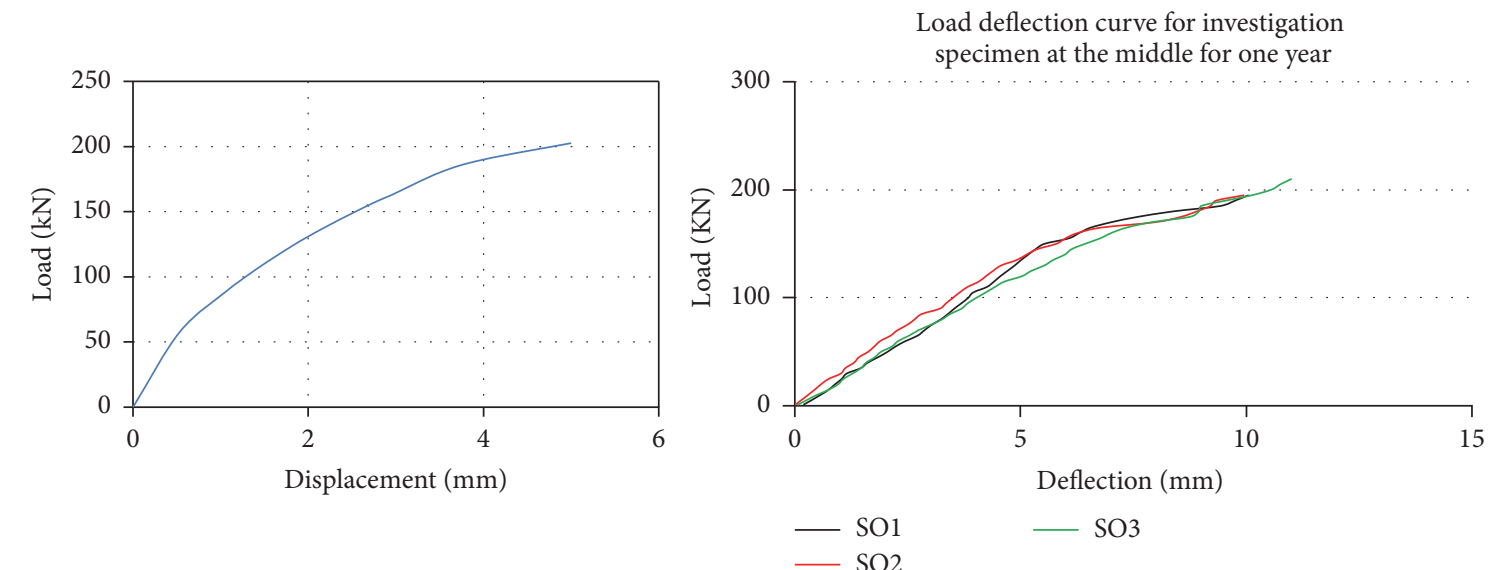

FIGURE 24: FEA and experimental load displacement curve for investigation specimen.

TABle 6: CDP Model Parameters.

\begin{tabular}{lcc}
\hline S. no. & Parameter & Value \\
\hline$(1)$ & Dilation angle & $36^{\circ}$ \\
$(2)$ & Eccentricity & 0.1 \\
$(3)$ & $f_{\text {bo }} / f_{\text {co }}$ & 1.16 \\
$(4)$ & $K$ & 0.667 \\
$(5)$ & Viscous parameter & 0 \\
\hline
\end{tabular}

(2) To reach the endeavor of productive environment in which human beings and nature can coexist in harmony, the way is to go green by producing green building materials for construction. The substitution of quarry dust and recycled aggregate will serve both solid waste management and waste recovery. This research has concluded that the incorporation of coated reinforcement with $50 \%$ replacement of both river sand and raw aggregate by using quarry dust and recycled aggregate yields positive results. As a result, the ultimate load carrying capacity of beams gets strengthened and the corrosion effect gets reduced, apart from other considerations of propagation of cracks, strains, and permeability.

(3) Stress-strain results are plotted in Figure 25 as per FEA. Based on the results of the numerical solutions and experimental data, it is concluded as follows: (a) results from the finite element simulation agree 


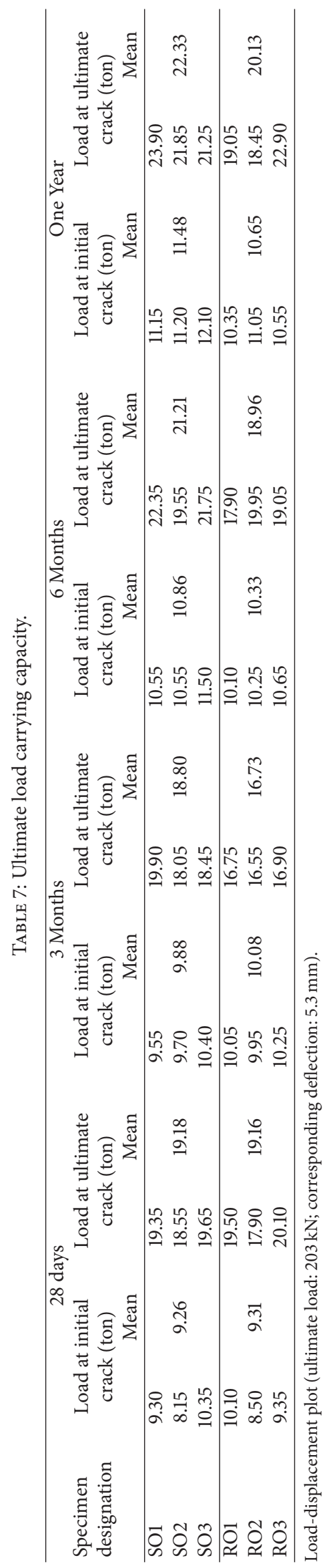



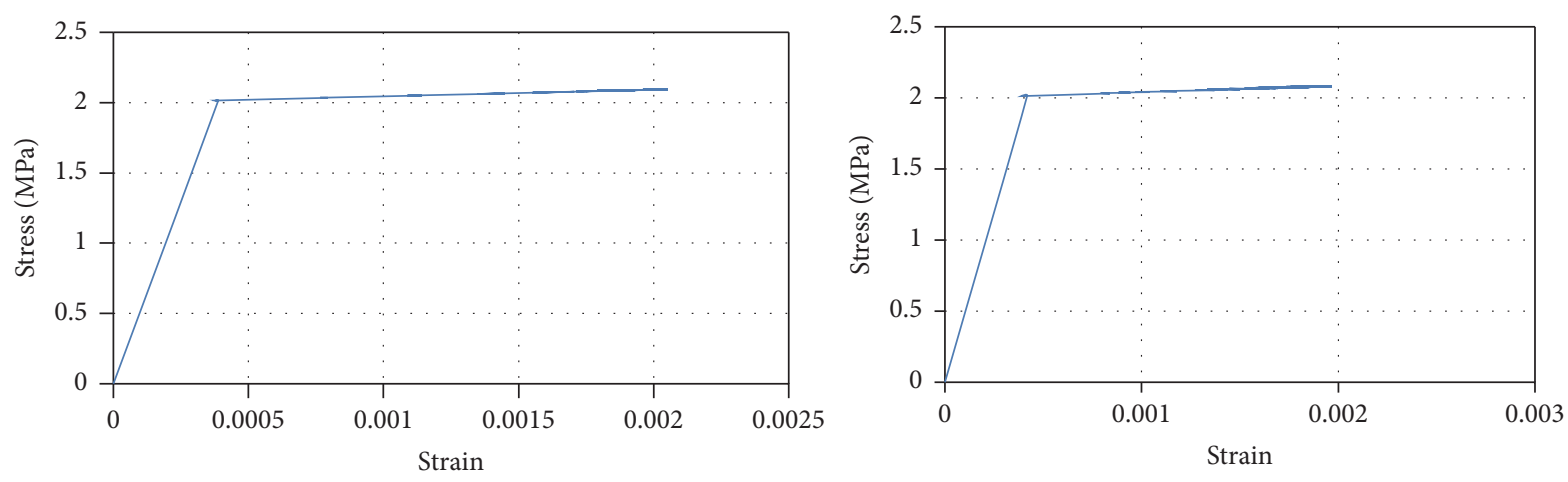

FIGURE 25: FEA stress-strain curve for controlled and investigation specimen.
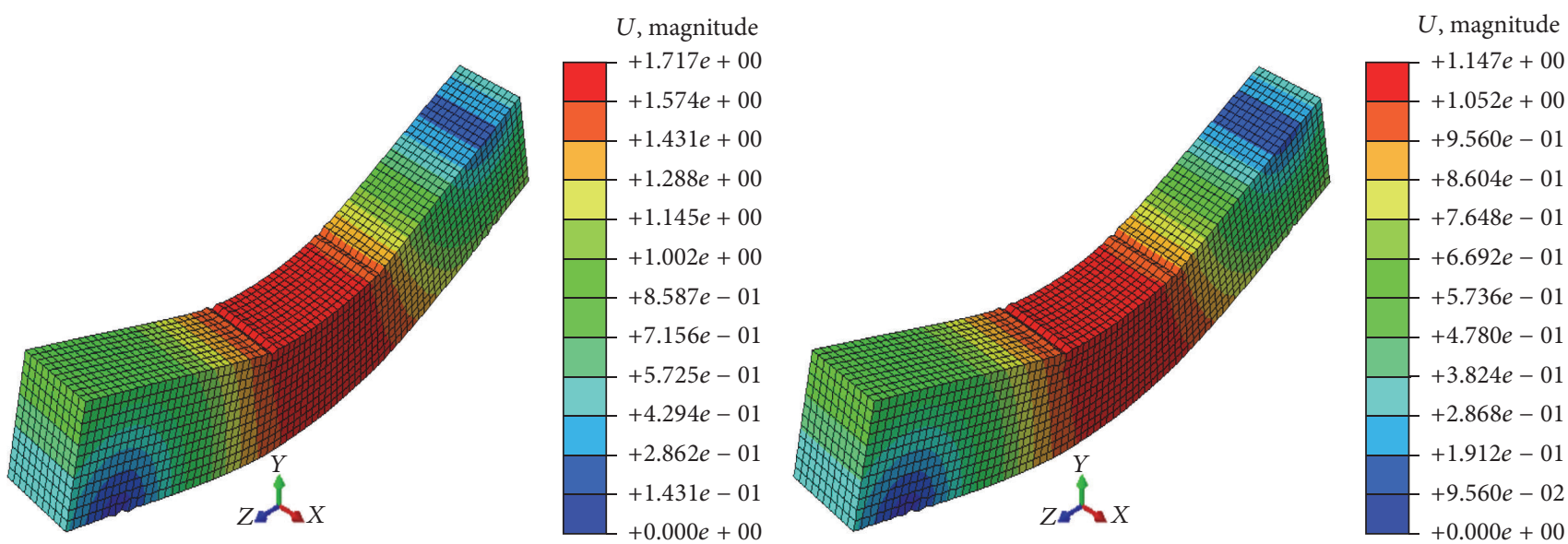

FIGURE 26: Deflected shape for controlled and investigation specimen.

with the experimental observation. Results for Von Mises stress, max principal stress, and max principal strain are plotted in Figures 18, 20, and 22. FEA ABAQUS may be used for the nonlinear analysis and design of structural elements very efficiently. (b) It is observed from experimental results that abundant reserve capacity is available after formation of initial crack. (c) Neutral axes are more than one during the time of loading and are found to be united at the stage of ultimate load. (d) Since nonlinearity persists at the time of loading, FEA is one of the appropriate techniques, which is used to compare the experimental results. (e) Future work shall include the formation of a constitutive model for time dependent effects such as rate of corrosion, creep, fatigue, crack propagation, shrinkage, and fire exposure.

\section{Competing Interests}

There is no conflict of interests regarding the publication of this manuscript.

\section{Acknowledgments}

This work has been carried out in Thiagarajar College of Engineering. The authors would like to acknowledge this institution for their support in this research.

\section{References}

[1] The Freedonia Group, Global demand for construction aggregates to exceed 48 billion metric tons in 2015, the concrete construction.

[2] Z. O. Tan, The Effect of Galvanized Steel Corrosion on the Integrity of Concrete, 2007.

[3] S. R. Yeoman, "Galvanized steel reinforcement in concrete-an overview," ILZRO Sponsored Project (ZE429), 2004.

[4] Y. Li, "Corrosion behaviour of hot dip zinc and zinc-aluminium coatings on steel in seawater," Bulletin of Materials Science, vol. 24, no. 4, pp. 355-360, 2001.

[5] D. Talbot and J. Talbot, Corrosion Science and Technology, Materials Science and Technology, 1997.

[6] CCANZ Recycled Aggregate in new Concrete 2011.

[7] C. Sukesh, K. B. Krishna, P. Sri Lakshmi Sai Teja, and S. Kanakanbara Rao, "Partial replacement of sand with quarry dust in concrete," International Journal of Innovative Technology and Exploring Engineering, vol. 2, no. 6, 2013.

[8] V. W. Y. Tam and C. M. Tam, "Diversifying two-stage mixing approach (TSMA) for recycled aggregate concrete: $\mathrm{TSMA}_{\mathrm{s}}$ and TSMA $_{\text {sc }}$, Construction and Building Materials, vol. 22, no. 10, pp. 2068-2077, 2008.

[9] V. W.-Y. Tam, X.-F. Gao, and C.-M. Tam, "Comparing performance of modified two-stage mixing approach for producing recycled aggregate concrete," Magazine of Concrete Research, vol. 58, no. 7, pp. 477-484, 2006. 
[10] I. Dumitru, T. Zdrilic, and G. Smorchevsky, "The use of manufactured quarry fines in concrete," in Proceedings of the 7th Annual Symposium on Aggregates-Concrete, Bases and Fines, International Centre for Aggregates Research (ICAR '99), C1-5-12, C1-5-1 pages, Austin, Tex, USA, 1999.

[11] ACI Manual of Concrete (ACI 212.3R-91) ASTM C494.IS 102621982 \& SP 23, Recommended Guidelines for Concrete mix, Bureau of Indian Standards, 1982.

[12] ACI, "Recommended guidelines for materials for concrete construction," ACI Manual of Aggregates for Concrete (ACI E199), 1999.

[13] P. B. Sakthivel, C. Ramya, and M. Raja, "An innovative method of replacing river sand by quarry dust waste in concrete for sustainability," International Journal of Scientific \& Engineering Research, vol. 4, no. 5, pp. 246-249, 2013.

[14] B. S. Waziri, A. G. Bukar, and Y. Z. A. Gaji, "Applicability of quarry sand as a fine aggregate in the production of medium grade concrete," Continental Journal of Engineering Sciences, vol. 6, no. 2, pp. 1-6, 2011.

[15] G. Balamurugan and P. Perumal, "Behaviour of concrete on the use of quarry dust to replace sand-an experimental study," Engineering Science and Technology, vol. 3, no. 6, pp. 776-781, 2013.

[16] A. Sivakumar and M. Prakash, "Characteristics studies on the mechanical properties of quarry dust addition in conventional concrete," Journal of Civil Engineering and Construction Technology, vol. 2, no. 10, pp. 218-235, 2011.

[17] M. Devi, "Performance evaluations of calcium nitrite on steel rebar corrosion in quarry dust concrete," Research Inventory in International Journal of Engineering and Science, vol. 2, no. 10, pp. 23-27, 2013.

[18] L. Nagpal, A. Dewangan, S. Dhiman, and S. Kumar, "Evaluation of strength characteristics of concrete using crushed stone dust as fine aggregate," International Journal of Innovative Technology and Exploring Engineering, vol. 2, no. 6, pp. 102-104, 2013.

[19] A. D. Pofale, "Syed raziuddin quadric. Effective utilization of crusher dust in concrete using portland pozzolana cement," International Journal of Science and Research, vol. 3, 2013.

[20] S. S. Kapgate and S. R. Satone, "Effect of quarry dust as partial replacement of sand in concrete," Indian Streams Research Journal, vol. 3, no. 5, 2013.

[21] P. N. Radhikesh, A. K. Das, and N. C. Moharana, Stone Crusher Dust as a Fine Aggregate in Concrete for Paving Blocks, 2010.

[22] R. Ilangovana, N. Mahendrana, and K. Nagamanib, "Strength and durability properties of concrete containing quarry rock dust as fine aggregate," ARPN Journal of Engineering and Applied Sciences, vol. 3, no. 5, pp. 20-26, 2008.

[23] S. Bhanu Pravalika and V. Lakshmi, "A study on fly ash concrete in marine environment," International Journal of Innovative Research in Science, Engineering and Technology, vol. 3, no. 5, pp. 12395-12401, 2014.

[24] O. O. Akinkurolere, J. O. Aribisala, O. L. Oke, and O. M. Ogundipe, "Construction waste recycling in sustainable engineering infrastructural development," International Journal of Development and Sustainability, vol. 2, no. 2, pp. 1066-1074, 2013.

[25] S. R. Yeoman, "Comparative studies of galvanized and epoxy coated steel reinforcement in concrete," in Proceedings of the 2nd International Conference on Durability of Concrete, Montreal, Canada, August 1991.

[26] S. R. Yeoman, "Considerations of the characteristics and use of coated steel reinforcement in concrete," 1993.
[27] S. R. Yeoman and M. P. Novak, "Comparative properties and behavior of galvanized and epoxy coated steel reinforcement," 1990.

[28] S. R. Yeoman, "Corrosion of the zinc alloy coating in galvanized reinforced concrete," in Corrosion 98, Paper 653, National Association of Corrosion Engineers, Houston, Tex, USA, 1992.

[29] M. M. Attard and S. Setunge, "Stress-strain relationship of confined and unconfined concrete," ACI Materials Journal, vol. 93, pp. 432-442, 1996.

[30] W. Guo, J. Zhang, and J. Zhuo, "A monotone scheme for high-dimensional fully nonlinear PDEs," The Annals of Applied Probability, vol. 25, no. 3, pp. 1540-1580, 2015. 

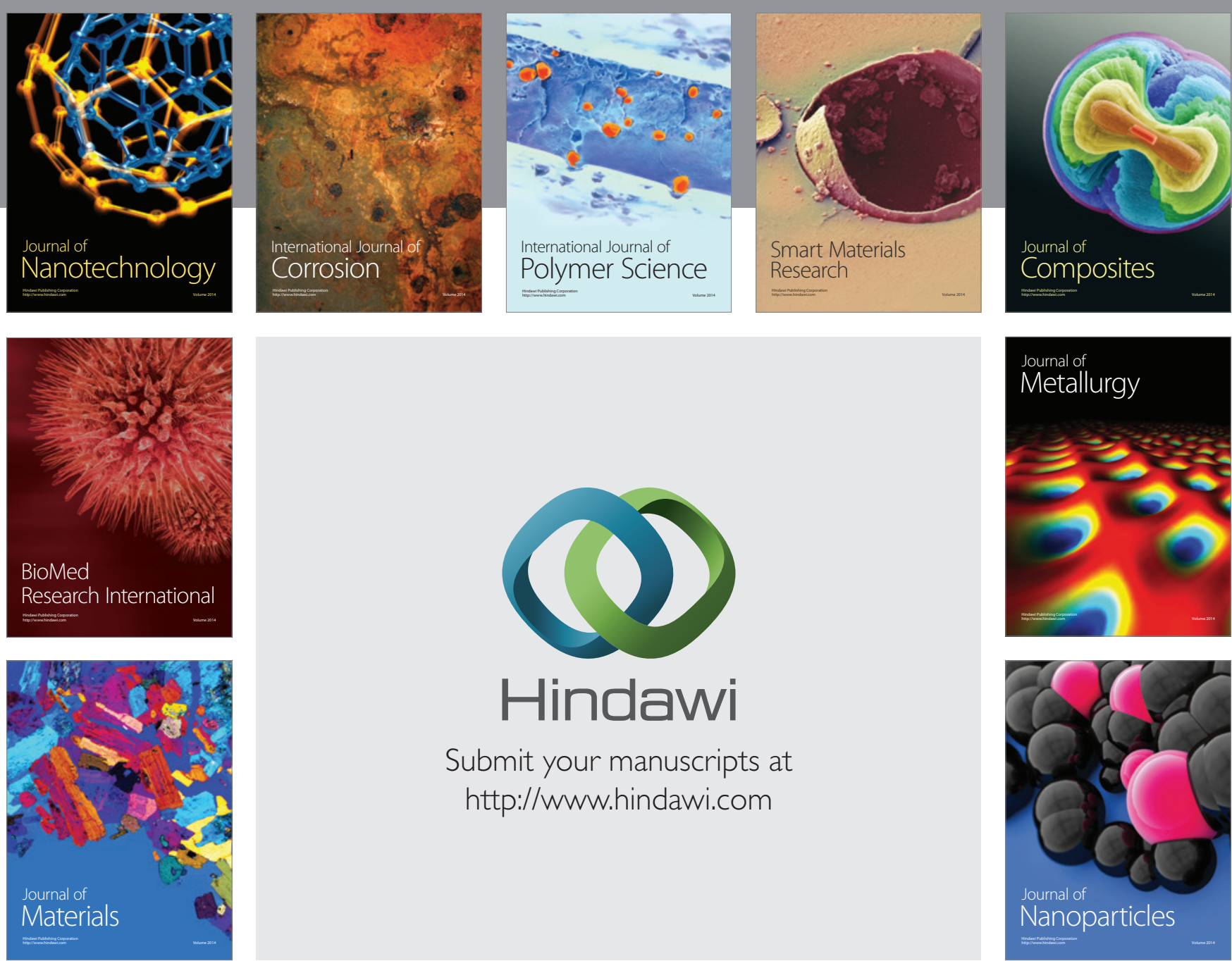

\section{Hindawi}

Submit your manuscripts at

http://www.hindawi.com

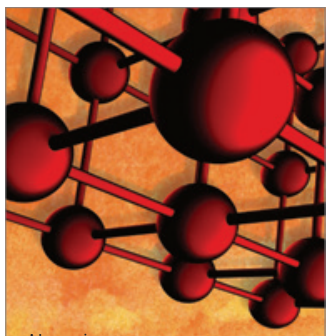

Materials Science and Engineering
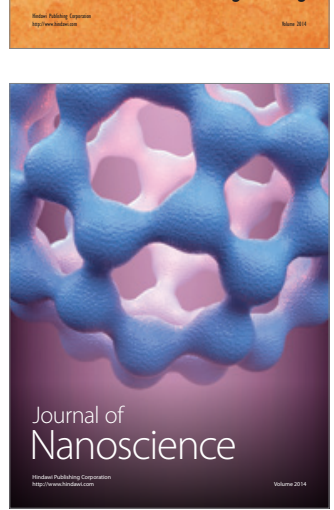
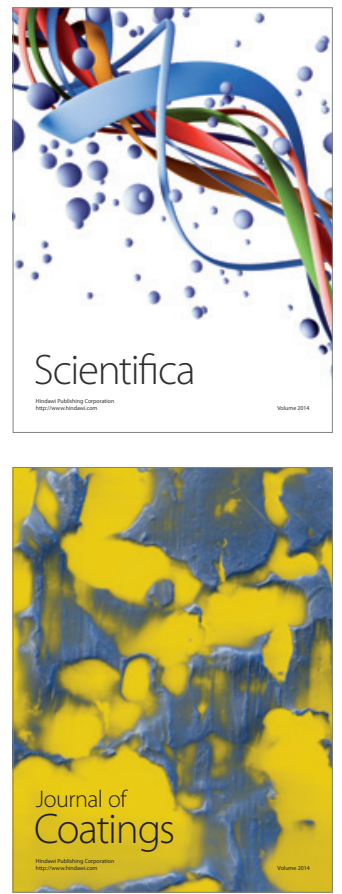
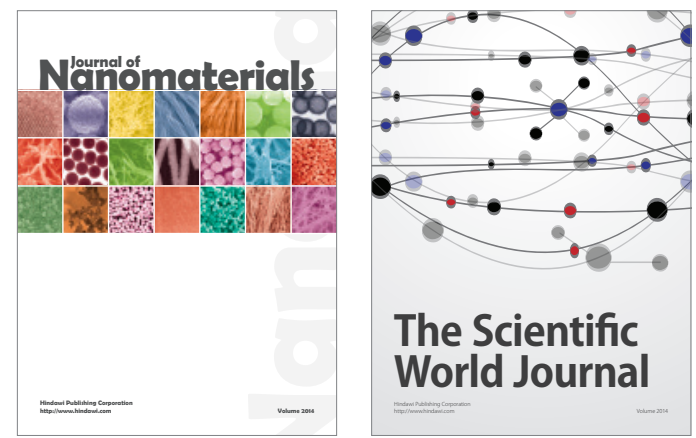

The Scientific World Journal
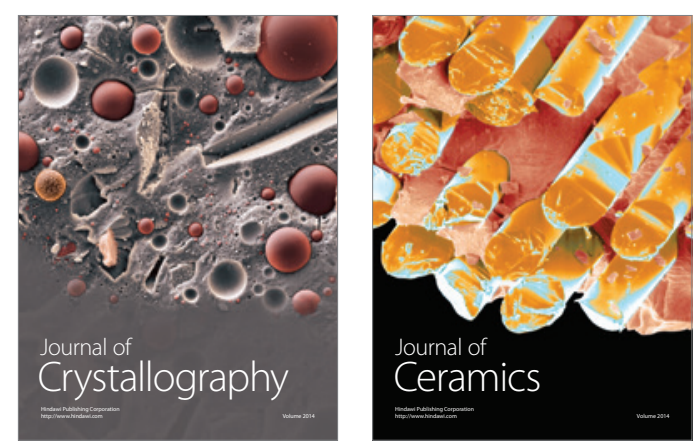
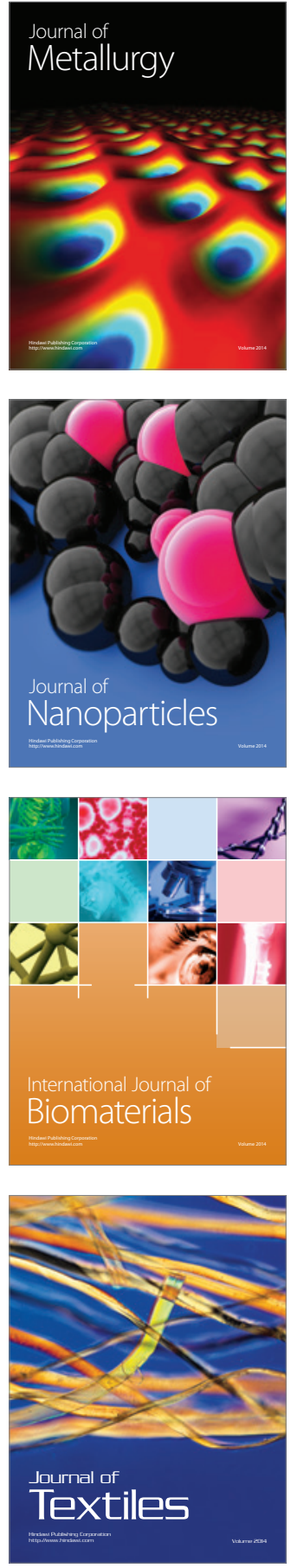